1 Anderson H, Esmail A, Hollowell J, Littlejohns P, Strachan D. Epidemiologically based needs assessment: lower respiratory disease. DHA project research programme, March 1993. p6-12.

2 Antibiotics and respiratory illness. [Editorial]. BMF 1974; iii: 1 .

3 British Thoracic Society. Community-acquired pneumonia in adults in British hospitals in 1982-1983: a survey of aetiology, mortality, prognostic factors hospitals in 1982-1983: a survey of aetiology,
and outcome. Quart f Med 1987;62:195-220.

4 Denny FW. Acute respiratory infections in children: etiology and epidemiology. Pediatrics in Review 1987;9:135-46.

5 Henderson FW. Viral infections of the respiratory tract. Current Opinion in Infectious Diseases 1992;5:183-5.

6 Nicholson KG, Baker DJ, Farquhar A, Hurd D, Kent J, Smith SH. Acute upper respiratory tract viral illness and influenza immunisation in homes for the elderly. Epidemiol Infect 1990;105:609-18.

7 Fang GD, Fine M, Orloff J, Arisumi D, Yu VL, Kapoor W, et al. New and emerging aetiologies for community-acquired pneumonia with implications for therapy: a prospective multicentre study of 359 cases. Medicine 1990;69:307-16.

8 Karalus NC, Cursons RT, Leng RA, Mahood CB, Rothwell RPG, Habcock B, et al. Community-acquired pneumonia: aetiology and prognostic index evaluation. Thorax 1991;46:413-8.

9 Burman LA, Trollfors B, Andersson B, Henrichsen J, Juto P, Kallings I, et al. Diagnosis of pneumonia by cultures, bacterial and viral antigen detection tests, and serology with special reference to antibodies against pneumococcal tests, and serology with special reference to

10 Woodhead MA. Management of pneumonia. Respir Med 1992;86:459-69.

11 Mansel JK, Rosenow EC, Smith TF, Martin JW. Mycoplasma pneumoniae pneumonia. Chest 1989;95:639-46.
12 Read RC. Pathogenesis of bacterial rspiratory infections. Current Opinion in Infectious Diseases 1993;6:141-5.

13 Boyle FM, Georghiou PR, Tilse MH, McCormack JG. Branhamella (Moraxella) catarthalis: pathogenic significance in respiratory infections. Med f Aust 1991;154:592-6.

14 Marrie TJ. Chlamydia pneumoniae. Thorax 1993;48:1-4.

15 Bourke SJ. Chlamydial respiratory infections. $B M$ F 1993;306:1219-20.

16 Carpenter JL. Klebsiella pulmonary infections: occurrence at one medical center and review. Rev Infect Dis 1990;12:672-82.

17 Woodhead MA, MacFarlane JT, McCracken JS, Rose DH, Finch RG. Prospective study of the aetiology and outcome of pneumonia in the community. Lancet 1987; ;:671-4.

18 Venkatesan P, MacFarlane JT. Role of pneumococcal antigen in the diagnosis of pneumococcal pneumonia. Thorax 1992;47:329-31.

19 Kalin M, Grandien M. Rapid diagnostic methods in respiratory infections. Current Opinion in Infectious Diseases 1993;6:150-7.

20 Woodhead M. The pneumonias. Current Opinion in Infectious Diseases 1992;5:164-9.

21 Woodhead $\mathrm{M}$. Antibiotic resistance in community-acquired pneumonia. $\mathrm{Br} \mathcal{F}$ Hosp Med 1992;47:684-7.

22 Andrew PW, Mitchell TJ, Myint SH. Prevention of respiratory infections. Current Opinion in Infectious Diseases 1993;6:146-9.

23 Graham NM. The epidemiology of acute respiratory infections in children and adults: a global perspective. Epidemiologic Reviews 1990;12:149-78.

(Accepted 29 November 1993)

\title{
Current Issues in Cancer
}

\section{Is there an epidemic of cancer?}

\section{David Coggon, Hazel Inskip}

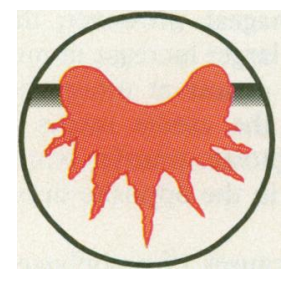

This is the first in a series of articles examining developments in cancer and updating what we know about the disease.

MRC Environmental Epidemiology Unit, University of Southampton, Southampton General Hospital, Southampton SO9 4XY

David Coggon, reader in occupational and environmental medicine Hazel Inskip, epidemiologiststatistician

Correspondence to: Dr Coggon.

Series editor: G M Mead (G M Mead is consultant in medical oncology at the Cancer Research Campaign's Wessex Medical Ohcology Unit)

BMf 1994;308:705-8
Trends in cancer mortality in England and Wales are dominated by a slowly evolving epidemic of lung cancer attributable to smoking. When the substantial effects of tobacco are discounted there is no evidence that the overall incidence of cancer is rising, but striking trends are apparent for several specific tumours. These may offer important clues to aetiology.

Among members of the general public the incidence of cancer is widely perceived to be rising. It is true that many more people die from the disease now than 100 years ago, but this is largely attributable to reductions in mortality from other causes. Cancer is for the most part an affliction of old age, and as longevity increases so will the number of cancer cases. To get a clearer picture we need to look at trends in death rates at different ages.

Not all cancers are fatal, and for those in which treatment has improved (for example, lymphoma and testicular cancer) mortality statistics must be interpreted with care. Also, allowance must be made for advances in diagnostic methods. For example, new imaging techniques may have led to better recognition of pancreatic tumours and thereby contributed to an apparent increase in mortality. Nevertheless, death rates are a good starting point for examining whether we really face a cancer epidemic.

\section{Trends in death rates at different ages}

Figure 1 shows the trends in overall cancer mortality in England and Wales during 1950-89 for five year age groups. In both males and females rates increased in elderly people but declined at younger ages. It turns out that this divergent pattern was determined mainly by changes in mortality from lung cancer, which contributes more deaths than any other tumour in men, and in women is second only to cancer of the breast.

Figure 2 shows age specific death rates from lung cancer, in this case plotted not against year of death but against year of birth (calculated simply by subtracting age at death from year of death). When the data are
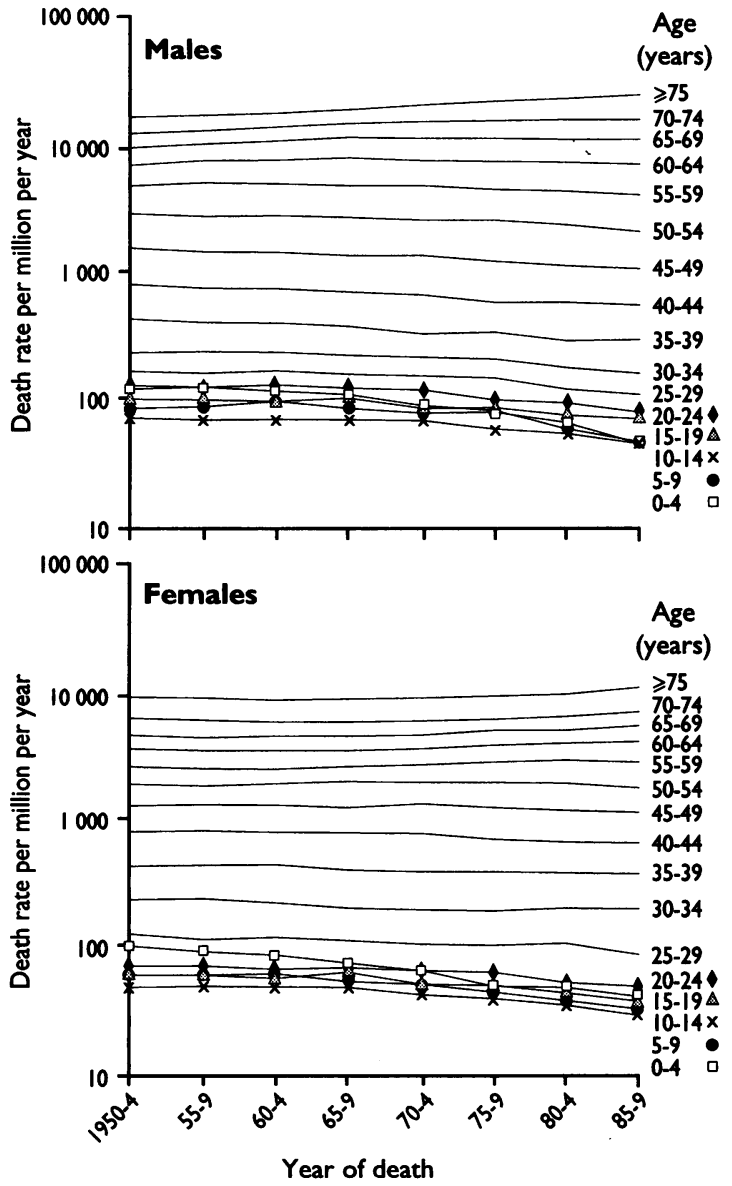

FIG 1-All cancer death rates by year of death, age, and sex

viewed thus it becomes clear that the generation of men born just after the turn of the century has experienced peak mortality from lung cancer at all ages. In women the pattern is similar but displaced to the right, so that the highest death rates occur in those born during the $1920 \mathrm{~s}$. The rise in mortality in the early generations can be attributed to the growing uptake of smoking, which 

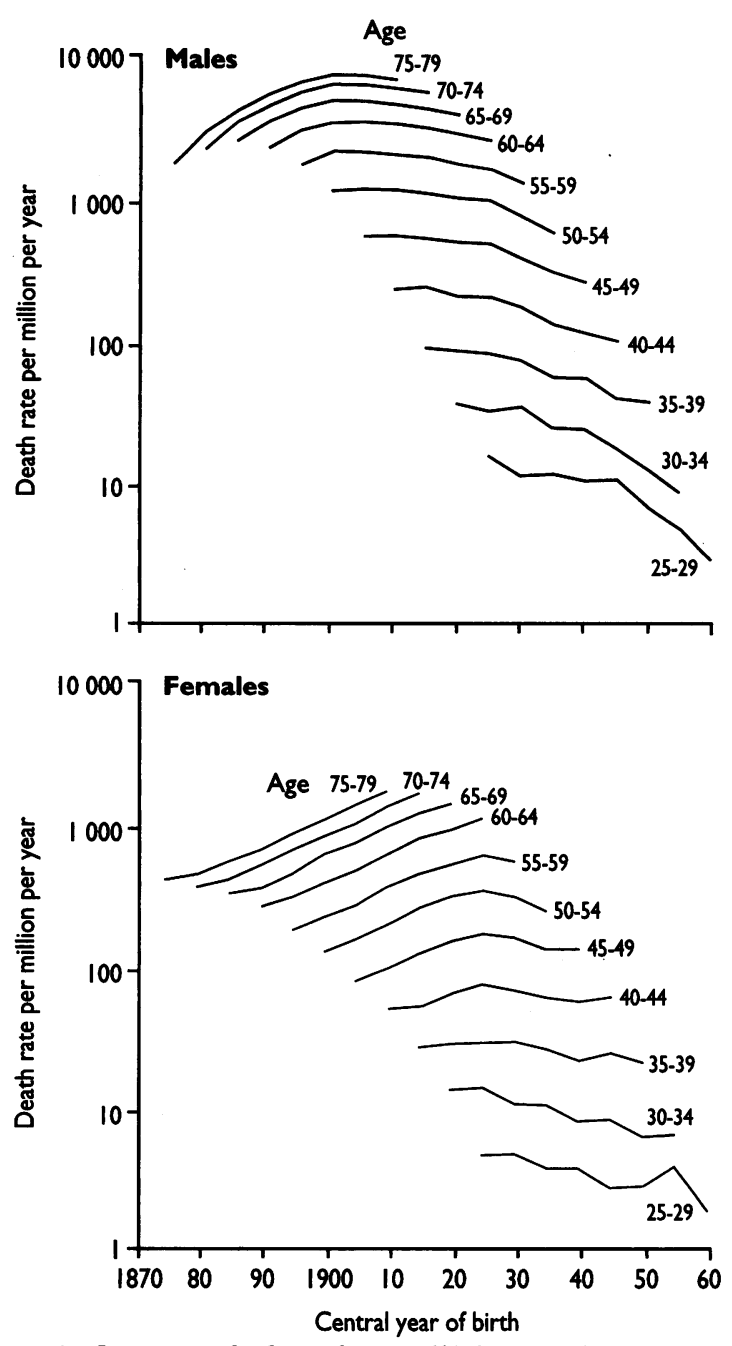

FIG 2-Lung cancer death rates by year of birth, age, and sex

reached its maximum later in women than in men. ${ }^{1}$ Why rates have fallen in those born later is more complicated. Decreases in tobacco consumption have not been large enough to account for all of the decline, and a more important influence may have been the introduction of filter tips and reductions in the tar content of cigarettes. On the basis of these trends mortality from lung cancer in older women is predicted to continue rising for some years yet. Already in Glasgow it has overtaken cancer of the breast as the most common malignancy in women. ${ }^{2}$ The eradication of smoking remains the first priority for the prevention of cancer in Britain.

Once deaths from lung cancer are discounted there is no evidence that total cancer mortality is increasing at any age. However, interesting trends are seen for specific types of cancer, some of which are becoming more common while others decline. We describe some of the most striking changes.

\section{Stomach cancer}

As recently as 1952 carcinoma of the stomach caused more deaths in England and Wales than any other cancer, but since then its incidence has decreased substantially at all ages, to the extent that mortality during $1985-9$ was less than $60 \%$ of that in 1950-4. ${ }^{34}$ Similar trends have been observed in other countries, but the reasons for this unplanned bonus to public health are not yet fully understood.

The most firmly established cause of stomach cancer is low consumption of fresh fruit and vegetables, ${ }^{5}$ and a contributing factor to the declining incidence may have been the greater year round availability of such foods in recent years. Another aspect of diet which has been linked with the disease is salt intake, ${ }^{56}$ and less frequent use of salt for food preservation-particularly with the advent of refrigerated food storage-may also have had a beneficial influence.

But changes in diet are not necessarily the whole answer. Recent epidemiological research indicates that the aetiology of stomach cancer also has an infectious component. Thus in follow up studies people with antibodies to the bacterium Helicobacter pylori were two to six times as likely to develop the disease as those without. ${ }^{7-9}$ Other research has shown that infection by $H$ pylori is most common in people brought up in crowded houses. ${ }^{10}$ And consistent with both these findings is the observation that the current geographical distribution of stomach cancer in England and Wales correlates with levels of domestic crowding in the 1930s. ${ }^{11}$ This suggests that the decline in stomach cancer could also be a long term consequence of improvements in housing, which have led to reduced transmission of $H$ pylori.

\section{Oesophageal cancer}

In contrast with cancer of the stomach, oesophageal cancer is becoming more common. Over the past 40 years death rates have increased at all ages, with an acceleration of the trend during the past decade, especially in men. ${ }^{34}$ Thus male mortality at ages 65-69 rose by $30 \%$ between 1986 and 1990 . In women the corresponding increase was $10 \%$. These changes might be explained if tumours of the gastro-oesophageal junction that previously were labelled as gastric are now being diagnosed as oesophageal. However, this would not account for the much larger increase in men than women. Moreover, unlike cancer at other sites in the stomach, carcinoma of the cardia seems to be growing in frequency. ${ }^{12}$ Diagnostic transfer would be expected to produce a trend in the opposite direction.

The most widely recognised causes of oesophageal cancer are alcohol and smoking, alcohol being the more likely to have contributed to the rise in mortality.

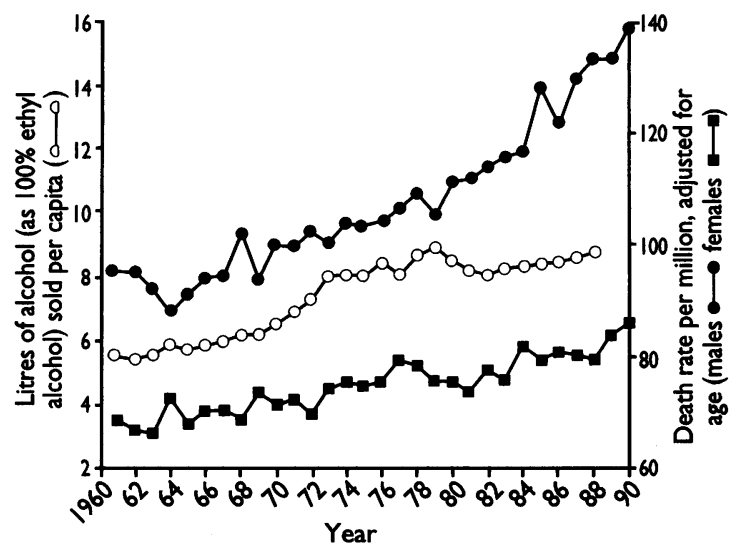

FIG 3-Age adjusted oesophageal cancer death rates for males and females, and per capita alcohol sales by year

Figure 3 shows trends in the per capita sales of alcohol during 1961-88 and death rates from cancer of the oesophagus up to 1990 . The pattern is consistent with an effect of alcohol on incidence, perhaps with a latency of 15-20 years. Alcohol consumption stabilised somewhat in the early $1980 \mathrm{~s}$, and it will be interesting to see whether this is reflected in a corresponding levelling off in mortality five to 10 years from now.

Whether risk of oesophageal cancer depends simply on the amount of alcohol consumed is not yet clear. Some studies have suggested that the type of alcoholic drink is also important, spirits being more harmful than beer and wine. ${ }^{13}$ 
Melanoma

Another cancer associated with increasing mortality is cutaneous melanoma. In both men and women death rates at ages over 40 rose threefold between 1950 and 1989. ${ }^{34}$ Rates have also increased at younger ages, though not so dramatically. As with lung cancer, risk appears to depend on year of birth, each successive generation up to those born in 1945 experiencing higher mortality than its predecessors. The most likely explanation is changing patterns of exposure to sunlight.

The evidence linking melanoma with solar radiation is manifold. Melanoma is predominantly a disease of fair skinned races, and in such people the anatomical distribution of tumours corresponds to patterns of sun exposure. Thus melanoma of the trunk is more common in men, while in women tumours are found more often on the leg. ${ }^{14}$ Furthermore, mortality is inversely related to latitude. This relation is particularly strong in Australia and North America, but is also apparent in Britain (fig 4). The picture is complicated, however, by the fact that mortality is higher in people with indoor occupations than in those who normally work outside. This has led to the hypothesis that intermittent exposure to sunlight is most hazardous, and that a tan conferred by regular exposure gives some protection. ${ }^{15}$ Comparisons of cases with controls who do not have the disease support this theory. In particular, a past history of sunburn seems to be associated with increased risk.

People are more exposed to sunlight now than in the past, partly because of changing fashions in dress and partly because of changes in leisure activities. For example, holidays in the sunshine of southern Europe have become much more popular over recent decades. Concern has been expressed that ozone depletion in the upper atmosphere and consequent increases in solar ultraviolet radiation at the earth's surface will in future lead to even higher rates of melanoma.

\section{Testicular cancer}

One of the most intriguing developments in cancer epidemiology is the emergence of testicular cancer from extreme rarity in the early years of this century to the point where it is now the most common malignancy

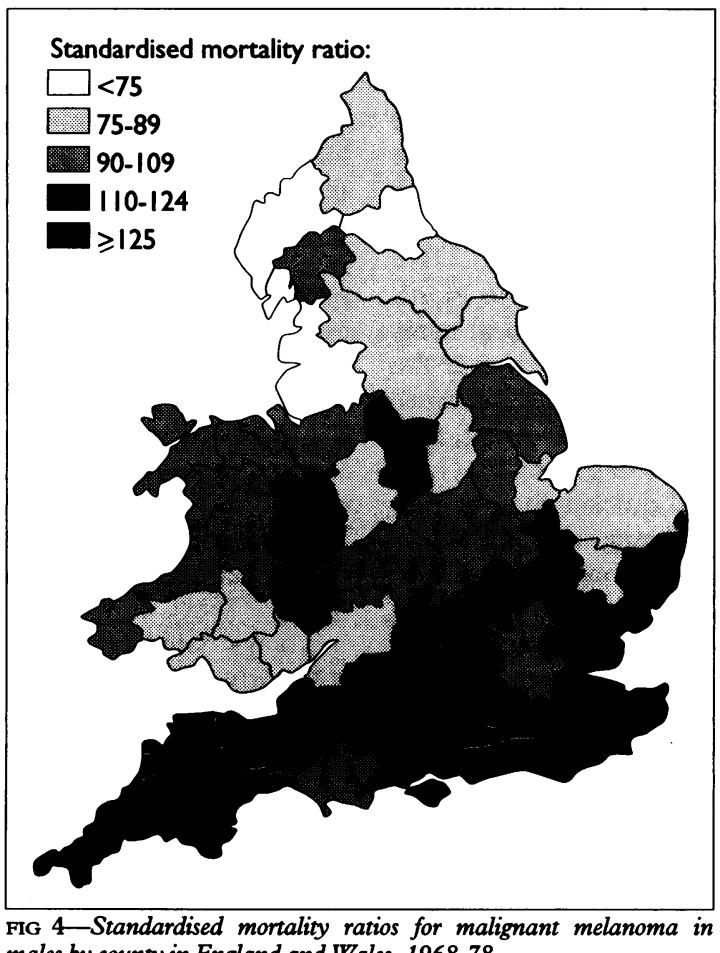

males by county in England and Wales, 1968-78

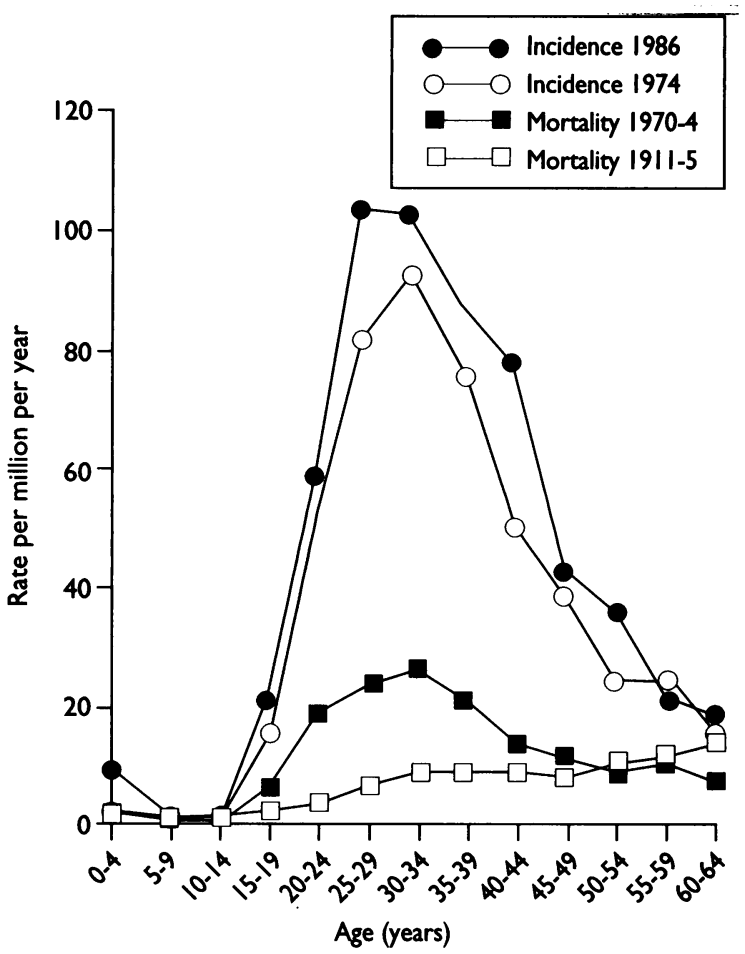

FIG 5-Testicular cancer mortality and incidence rates by age in different time periods

in young men. ${ }^{16}$ Documentation of the trend is complicated by the rapid advances in treatment, which have made the disease now largely curable. Changes in incidence over the past 20 years are therefore better assessed from data on cancer registrations than from mortality statistics. Figure 5 illustrates the evolution of the epidemic.

The environmental changes underlying this trend must have begun at least as early as 1911 , and may still be continuing. Various explanations have been proposed, but none has yet been confirmed. One idea attributes the rise to changing styles of underwear. Another, more attractive hypothesis postulates that risk is related to maternal weight, differences in adiposity influencing the endocrine environment of the developing fetus and initiating changes which predispose to later malignancy. Better nutrition of mothers might in this way explain the rise not only in testicular cancer but also in the incidence of testicular maldescent. Maldescended testes are more prone to malignant change, ${ }^{17}$ but any increased incidence of maldescent can explain only a small part of the rise in testicular cancer.

\section{Cancer of the brain and nervous system}

Another tumour with rising mortality is primary cancer of the brain and nervous system. The increase has occurred in both sexes and is most pronounced in the 70-74 age group, in whom rates rose more than sixfold between 1950 and $1989 .{ }^{34}$ Similar trends have been observed in the United States, Japan, France, Italy, and West Germany. ${ }^{18}$

During the past 20 years there have been important developments in techniques for investigating intracranial disease, with the growing use of radioisotope scans and later of computed tomography and magnetic resonance imaging. These changes may have led to better recognition of primary brain tumours that previously would have been diagnosed as stroke or metastatic disease. However, such artefacts of diagnosis are unlikely to provide a complete explanation for the trend, which began at least as early as 1950 .

Very little is known about the causes of brain cancer. Follow up studies have shown high rates of the disease 
in people who as children were treated with depilatory radiation for ringworm of the scalp,,$^{19} 20$ but changes in the overall exposure of the general population to ionising radiation are insufficient to have had a major impact on brain cancer incidence. More recently, brain cancer has been linked with exposure to magnetic fields from electrical equipment. ${ }^{21}$ However, the evidence for a relation is far from convincing. In particular, it is not clear how magnetic fields would influence the biochemistry of cells in such a way as to initiate or promote cancer formation. As yet, therefore, the trends in brain cancer mortality are not satisfactorily explained.

\section{Conclusions}

Analysis of age specific death rates confirms that we are experiencing a true epidemic of cancer but suggests that this is attributable largely to smoking. On the basis of current trends the epidemic can be expected to decline first in men and later in women. There is no evidence that toxic hazards such as pesticides, chemical waste, and other forms of industrial pollution have had a major impact on overall rates of cancer. Some specific cancers do show remarkable changes in incidence and mortality, and it is important to monitor these for the clues they can give us to aetiology and so that the provision of health care can be better planned.

1 Coggon D, Acheson ED. Trends in lung cancer mortality. Thorax 1983;38: 721-3.

2 Gillis CR, Hole DJ, Lamont DW, Graham AC, Ramage S. The incidences of lung cancer and breast cancer in women in Glasgow. BMY 1992;302:1331. 3 Osmond C, Gardner MI, Acheson ED, Adelstein AM. Trends in cancer mortality 1951-1980: analysis by period of birth and death. London: HMSO, 1983. (OPCS series DH1, No 11.)

4 Office of Population Censuses and Surveys. Mortality staristics, cause 1981-1990. London: HMSO, 1983-1991. (Series DH2, Nos 8-17.)

5 Howson CP, Hiyama T, Wynder BL. The decline in gastric cancer. epidemiology of an unplanned triumph. Epidemiol Rev 1986;8:1-27.

6 Coggon D, Barker DJP, Cole RB, Nelson M. Stomach cancer and food storage. I Natl Cancer Inst 1989;81:1178-82.

7 Forman D, Newell DG, Fullerton F, Yamell JWG, Stacey AR, Wald N, et al. Association between infection with Helicobacter pylori and risk of gastric cancer: evidence from a prospective investigation. BMF 1991;302:1302-5.

8 Parsonnet J, Friedman GD, Vandersteen DP, Chang Y, Vogelman JH, Orentreich $N$, et al. Helicobacter pylori infection and risk of gastric Orentreich N, et al. Helicobacter pylori
carcinoma. N Engl f Med 1991;325:1127-31.

9 Nomura A, Stemmermann GN, Chyou PH, Kato I, Perez-Perez GI, Blaser MJ. Helicobacter pylori infection and gastric carcinoma among Japanese Americans in Hawaii. N Engl I Med 1991;325:1170-1.

10 Mendall MA, Goggin PM, Molineaux N, Levy J, Toosy T, Strachan D, et al. Childhood living conditions and Helicobacter pylori seropositivity in adult life. Lancet 1992;339:896-7.

11 Barker DJP, Coggon D, Osmond C, Wickham C. Poor housing in childhood and high rates of stomach cancer in England and Wales. Br I Cancer 1990;61:575-8.

12 Powell J, McConkey CC. Increasing incidence of adenocarcinoma of the gastric cardia and adjacent sites. Br $\mathcal{F}$ Cancer 1990;62:440-3.

13 Day NE, Munoz N. Esophagus. In: Schottenfeld D, Fraumeni JF, eds. Cancer epidemiology and prevention. Philadelphia: W B Saunders, 1982:596-623.

14 Lee JAH. Melanoma. In: Schottenfeld D, Fraumeni JF, eds. Cancer epidemiology and prevention. Philadelphia: W B Saunders, 1982:984-5.

15 Armstrong BK. Epidemiology of malignant melanoma: intermittent or total accumulated exposure to the sun? Y Dermatol Surg Oncol 1988;14:835-49.

16 Davies JM. Testicular cancer in England and Wales: some epidemiologica aspects. Lancet 1981 ; $: 928-31$.

17 Swerdlow AJ, Huttley SRA, Smith PG. Testicular cancer and antecedent disease. Br 7 Cancer 1987;55:97-103.

18 Davis DL, Hoel D, Fox J, Lopez A. International trends in cancer mortality in France, West Germany, Italy; Japan, England and Wales, and the USA Lancet 1990;336:474-81.

19 Modan B, Baidatz D, Mart H, Steinitz R, Levin SG. Radiation-induced head and neck tumours. Lancet 1974;i:277-9.

20 Shore RE, Albert RE, Pasternack BS. Follow-up study of patients treated by $X$-ray epilation for tinea capitis: resurvey of post-treatment illness and X-ray epilation for tinea capitis: resurvey of post-t
morality experience. Anch Environ Health 1976;31:21-8.

21 National Radiological Protection Board. Electromagnetic fields and the risk of cancer. Documents of the NRPB 1992;3:1-138.

\section{Community Care: The First Year}

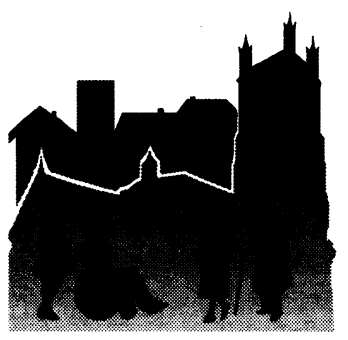

This is the first of a series of four articles looking at what has happened in community care over the past year.

\section{Community care in Bassetlaw}

\section{Trish Groves}

Last April the United Kingdom's system for providing community care-practical and social care for ill and disabled people who need help with daily lifewas changed in an efiort to make it better and more efficient. 1 The $B M J$ ran a series of articles about the changes that included descriptions of community care in four places: Gwent in Wales, Bassetlaw in Nottinghamshire, Northern Ireland, and Newcastle in north east England. ${ }^{2-5}$ In this and the next three articles we look at what has happened to community care over the past year in these places.

Most people in Bassetlaw, a council district in North Nottinghamshire, would probably say that local community care services have not changed much over the past year. But some local residents, for instance, those needing extra help at home after leaving hospital, may have noticed that the whole process of getting that help has become easier and, perhaps, quicker than before. The various organisations arranging and providing care have been working hard to communicate and cooperate more effectively and to find the most workable way of giving local people what they need. This planning work behind the scenes should improve services gradually but is already smoothing the potentially problematic processes of referring and assessing people for care.

\section{British Medical Journal,} London WC1H 9JR

Trish Groves, assistant editor

BMf 1994;308:708-11
"If you'd talked to me a year ago about district planning for community care in Bassetlaw I'd have been tearing my hair out," says David Whitham, chair of the Bassetlaw district joint planning team, which consists of representatives from health and local authorities, the family health services authority, users, carers, and voluntary groups. "But I've been immensely encouraged because the planning team has stuck to its timetable and its members have really concentrated on coming up with a broad response to local people's needs, rather than pushing too hard for the interests of the groups they represent."

Over the past year the team has got to grips with the politics and jargon of planning, recommended how to spend the joint finance budget, and agreed on and sent out for consultation next year's community care plan. The team has got on well partly because its members have worked hard and enthusiastically. It has also benefited from Bassetlaw's long history of successful joint working and serving a mainly rural district scattered around two market towns (see map). There has never been a big and powerful town hall or hospital locally to dominate planning for community care.

Things could get tougher in future, however. "It's still early days," says David Whitham. "The main issue for the team now is to audit existing services and try to match resources to the needs of Bassetlaw's people. We're looking at the local situation by using information like the census, public health data, and needs assessments. We're also recording all unmet needs that arise during individual assessment, but we realise that there may not be enough money to let us fulfil all those unmet needs in the long term. The 